\title{
Review
}

\section{Challenges and Perspectives in the Management of Late-Stage Parkinson's Disease}

\author{
Margherita Fabbri ${ }^{\mathrm{a}, \mathrm{b}, *}$, Linda Azevedo Kauppila ${ }^{\mathrm{c}}$, Joaquim J. Ferreira ${ }^{\mathrm{b}, \mathrm{d}, \mathrm{e}}$ and Olivier Rascol ${ }^{\mathrm{a}}$ \\ ${ }^{a}$ Department of Neurosciences, Clinical Investigation Center CIC 1436, Parkinson Toulouse \\ Expert Centre, NS-Park/FCRIN Network and Neuro Toul COEN Centre; Toulouse University Hospital; \\ INSERM; University of Toulouse 3; Toulouse, France \\ ${ }^{\mathrm{b}}$ Laboratory of Clinical Pharmacology and Therapeutics, Faculdade de Medicina, Universidade de Lisboa, \\ Lisbon, Avenida Professor Egas Moniz, Lisbon, Portugal \\ ${ }^{\mathrm{c}}$ Department of Neurosciences and Mental Health, Neurology, Hospital de Santa Maria, \\ Centro Hospitalar Universitário Lisboa Norte, Lisbon, Portugal \\ ${ }^{\mathrm{d}}$ CNS - Campus Neurológico Sénior, Torres Vedras, Portugal \\ ${ }^{\mathrm{e}}$ Instituto de Medicina Molecular João Lobo Antunes, Lisbon, Portugal
}

Accepted 20 May 2020

\begin{abstract}
Parkinson's disease (PD) is a common neurodegenerative disorder, with a continuously increasing prevalence. With improved clinical and therapeutic management of PD, more patients reach later stages of the disease, meaning they may face new clinical problems that were not commonly approached. This gave way to the description of a new PD stage, late-stage PD (LSPD), which is clinically discernible from the advanced-stage one. Therefore, LSPD patients have new and different needs, regarding pharmacological and non pharmacological interventions, including palliative care and multidisciplinary teams. LSPD patients constitute an 'orphan population', who traditionally was excluded from previous studies, due to its high disability. With this manuscript, we intend to review specific management challenges of LSPD patients, covering this new concept and its clinical features, how to assess these patients, therapeutic recommendations, as well as discussing ongoing research and future perspectives.
\end{abstract}

Keywords: Parkinson's disease, late-stage, palliative care, multidisciplinary care, caregivers

\section{INTRODUCTION}

Parkinson's disease (PD) is the second most common age-related neurodegenerative disorder after Alzheimer's disease, and its prevalence is expected to increase up to 12.9 million by 2040 [1]. As a

\footnotetext{
*Correspondence to: Margherita Fabbri, MD, PhD,Toulouse University Hospital, University of Toulouse 3, Hôpital Pierre Paul Riquet, place du Dr Baylac, 31059 Toulouse, France. Tel.: +33 561776039; E-mails: margheritafabbrimd@ gmail.com; fabbri.m@chu-toulouse.fr
}

reflection of increased life expectancy and a better clinical management, the number of old PD patients or patients with a more prolonged disease course is estimated to increase, carrying a higher burden of disease for patients, caregivers, and healthcare systems [2]. The aim of this viewpoint is to illustrate the main clinical features, treatment challenges and future research perspectives for late-stage (LS) PD patients, a recently described PD stage, which actually represents an "orphan population", usually not included in clinical trials or observational studies, due to its great disability [2]. 


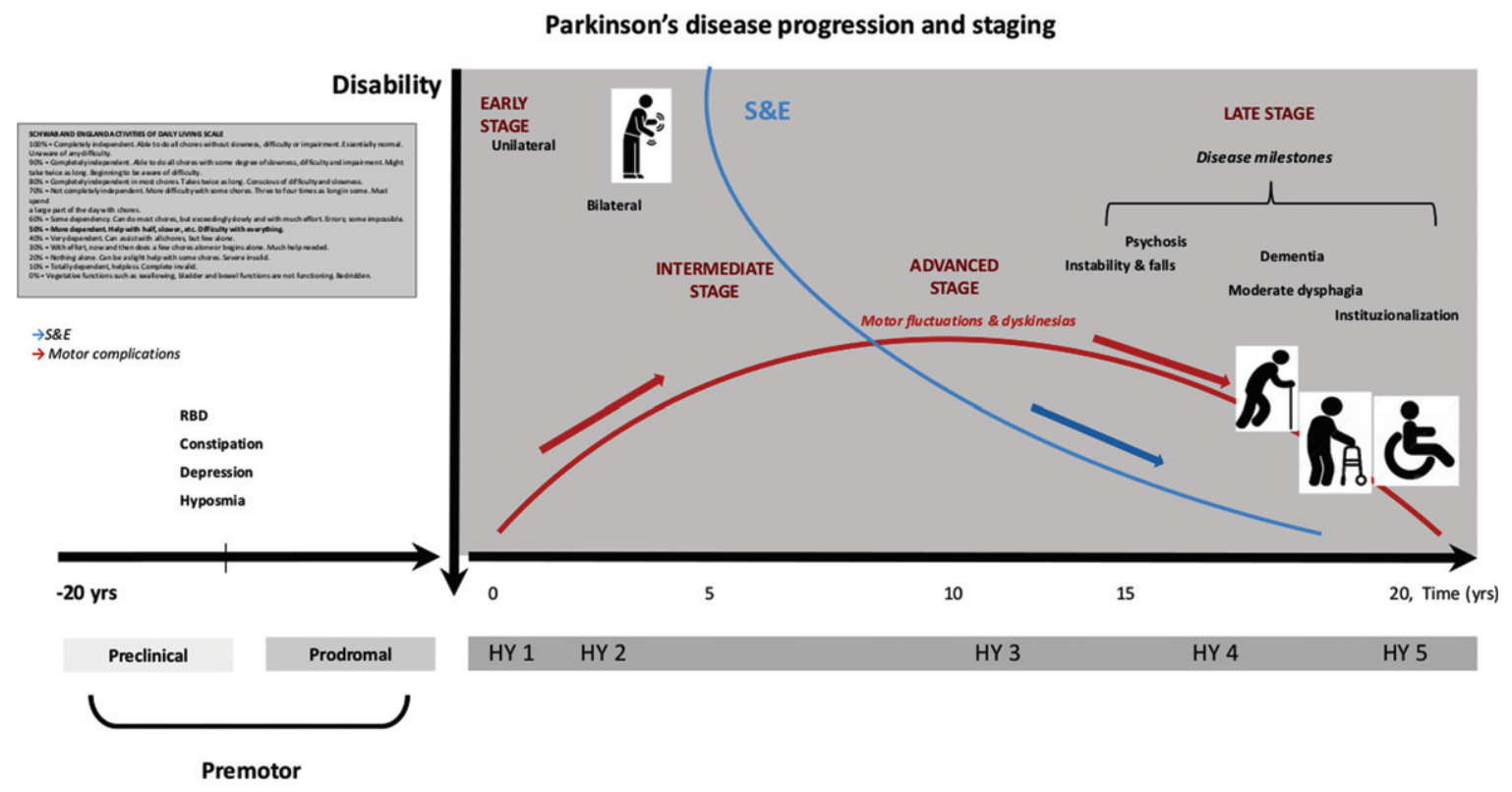

Fig. 1. PD staging progression.

\section{PARKINSON'S DISEASE STAGING}

PD motor progression is non-linear (Fig. 1) and more pronounced in patients with cognitive dysfunction or older age at onset [3] and faster in the LS if compared to the advanced one [4].

Classically, PD progression is marked by the severity of motor symptoms, appearance of patients' physical dependence and motor complications (MCs), whose severity classically define the beginning of the advanced PD stage [5, 6], as well as reaching a Hoehn and Yahr stage (HY) of 4 or 5 in the "Med Off" condition [4]. However, it may occur that patients displaying different disease severities, may be included in the same HY stage, as the HY does not consider the presence of non-motor symptoms (NMS) or MCs, whose prevalence increase with disease progression [7]. Indeed, besides MCs, PD patients in advanced stage also manifest several NMS and axial motor features, such as postural instability, freezing of gait (FoG), falls and dysphagia $[6,8]$ (Fig. 1).

\section{LATE-STAGE PARKINSON'S DISEASE CONCEPT AND CLINICAL FEATURES}

In the last two decades, it has been observed that a small subset of advanced PD patients progress to a later phase of the disease, clinically discernible from the previous one [2]. LSPD patients usually present a severe bradykinesia with reduced or absent appendicular rigidity $[9,10]$. Disability from MCs is reduced, because these complications attenuate naturally, either due to levodopa treatment reduction or in response to device-aided therapies [11, 12]. Conversely, disability is related to a cluster of variables that consists of NMS, as cognitive impairment, psychosis, depression, daytime sleepiness, autonomic dysfunction, and axial symptoms poorly responsive to levodopa. Taken as a whole, we have a "late" phenotype whose clinical features do not really fit with the common concept of idiopathic PD, but rather sharing common clinical elements with atypical parkinsonisms (Table 1) $[2,13]$.

\section{Which are the most relevant clinical problems?}

Four principal disability milestones, i.e., symptoms of disease progression that should draw additional medical attention, have been identified to precede death by around 5 years, independently from disease duration and age of onset: visual hallucinations (5.1 years), falls (4.1 years), dementia (3.3 years), and institutionalization (3.3 years) [14]. Other recognized red flags for a poor outcome are the need for a formal caregiver and the presence of swallowing problems [4]. The presence of dementia predicts a blunted or absent levodopa response [15], though 
Table 1

Late-stage PD: clinical and therapeutic key points

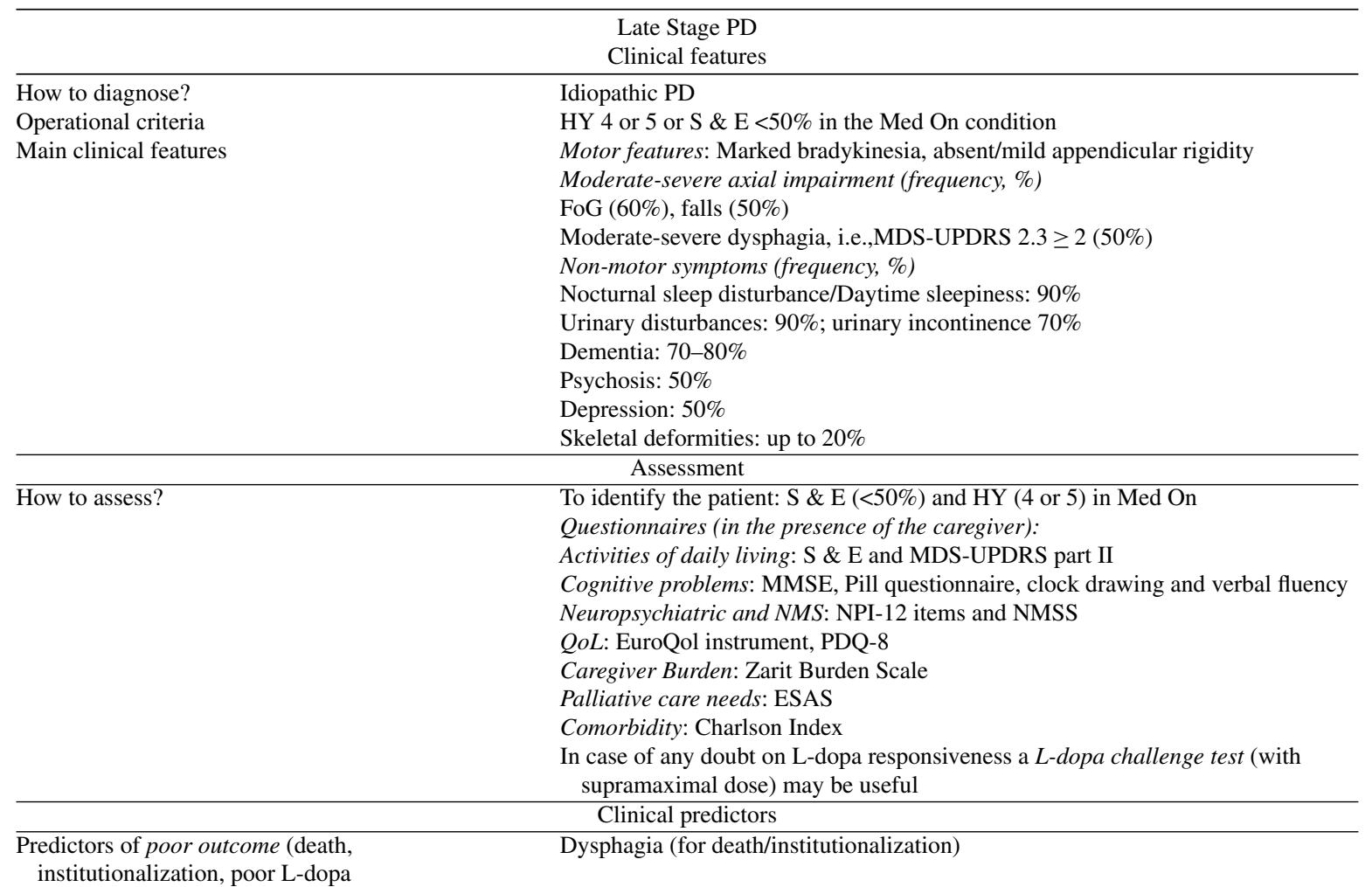

institutionalization, poor L-dopa responsiveness)

Dementia (for institutionalization, death and L-dopa response)

Falls (for death/institutionalization)

Institutionalization (for death/institutionalization)

Hallucinations (for death/institutionalization)

A worse L-dopa response does not predict a worse outcome

Predictors of good therapeutic

Dyskinesia are related to a moderate/better L-dopa responsiveness

response

\begin{tabular}{|c|c|}
\hline \multicolumn{2}{|r|}{ Treatment and recommendations } \\
\hline \multicolumn{2}{|r|}{ Motor symptoms } \\
\hline \multirow[t]{5}{*}{$\begin{array}{l}\text { Parkinsonism (rigidity, bradykinesia, } \\
\text { tremor) }\end{array}$} & $\begin{array}{l}\text { L-dopa: } 11 \%-18 \% \text { improvement at the MDS-UPDRS part III at an acute } \\
\text { challenge test: moderate effect on tremor and rigidity, but mild/absent effect on } \\
\text { bradykinesia and axial symptoms; }\end{array}$ \\
\hline & Nonpharmacological treatments (no study in LSPD patients): \\
\hline & $\begin{array}{l}\text { Physiotherapy }{ }^{+} \text {, Movement strategy based-exercise }{ }^{\ll, \#}, \text { Formalized patterned } \\
\text { exercise }{ }^{\ll, \#}, \text { Occupational therapy }{ }^{\ll, \#},(\text { no specific study in LSPD) }\end{array}$ \\
\hline & $\begin{array}{l}\text { Recommendations: a) if clinically required due the persistence of tremor/rigidity, } \\
\text { try augmentation of L-dopa dose, among patients with very mild dyskinesia; b) } \\
\text { try to maintain L-dopa monotherapy, if necessary use L-dopa add-on therapies } \\
\text { (DAAs, IMAO-B, COMT-I) at lowest effective dose, monitoring AEs. }\end{array}$ \\
\hline & Try to implement Physiotherapy \\
\hline \multirow[t]{6}{*}{ FoG \& Gait disturbance } & $L$-dopa (for Off period $\mathrm{FoG})$ \\
\hline & Nonpharmacological treatments \\
\hline & $\begin{array}{l}\text { Physiotherapy }{ }^{+} \text {, Rhythmic auditory cues and visual cues }{ }^{\text {LevelC }} \text {, Walker or stick } \\
\text { projecting a laser line on the floor }{ }^{\text {LevelC }} \text { (no study in LSPD) }\end{array}$ \\
\hline & Occupational therapy \\
\hline & Home adjustment GPP \\
\hline & $\begin{array}{l}\text { Recommendations: try to increase L-dopa, implement Physiotherapy and verify } \\
\text { home adjustment feasibility }\end{array}$ \\
\hline
\end{tabular}


Table 1

(continued)

\begin{tabular}{|c|c|}
\hline \multicolumn{2}{|r|}{$\begin{array}{l}\text { Late Stage PD } \\
\text { Clinical features }\end{array}$} \\
\hline \multicolumn{2}{|r|}{ Non-motor symptoms } \\
\hline Dementia & Acetylcholinesterase inhibitors: Rivastigmine ${ }^{\S,+}$, Donepezil \& galantamine ${ }^{\ll, \#}$ \\
\hline Psychosis & $\begin{array}{l}\text { Clozapine \& Pimavanserin }{ }^{\S,+} \\
\text { Quetiapine } «, \#\end{array}$ \\
\hline Depression & $\begin{array}{l}\text { Tricyclic antidepressants: Nortriptyline, desipramine }{ }^{` \#} \\
\text { SSRI/SSNRI: Venlafaxine } \mathrm{e}^{\S,+} \text {, Citalopram, sertraline, paroxetine, fluoxetine }{ }^{«, \#} \\
\text { DAA: Pramipexole }{ }^{\S,+} \text { (cautious use, monitor AEs) }^{\text {(a) }}\end{array}$ \\
\hline Apathy & Rivastgimine $^{\S, \#}$ \\
\hline \multirow[t]{7}{*}{ Orthostatic hypotension } & Droxidopa $^{\S, \#}$ \\
\hline & Fludrocortisone \& midodrine ${ }^{\ll, \#}$ \\
\hline & $\begin{array}{l}\text { Recommendations: Before using drugs, adopt behavioural adaptation } \longrightarrow \text { avoid } \\
\text { aggravating factors such as large meals, alcohol, warm environment, volume } \\
\text { depletion, diuretics, antihypertensive drugs, DAAs, tricyclic antidepressants, } \\
\text { nitrates and alpha-blockers used to treat prostatic hypertrophy. }\end{array}$ \\
\hline & Increase salt intake, head-up tilt of the bed at night $\left(30-40^{\circ}\right)$; \\
\hline & Wear waist-high elastic stockings and/or abdominal binders; \\
\hline & Exercise as tolerated; \\
\hline & Introduce counter manoeuvres (leg crossing, toe raising, thigh contraction) \\
\hline \multirow[t]{2}{*}{ Speech disorders } & $\begin{array}{l}\text { Speech therapy",\# (Lee Silverman Voice Therapy may improve vocalintensity and } \\
\text { phonation, but no study in LSPD patients). }\end{array}$ \\
\hline & L-dopa: no effect \\
\hline \multirow[t]{6}{*}{ Dysphagia } & Only GPP level \\
\hline & Optimize dopaminergic therapy \\
\hline & $\begin{array}{l}\text { Conservative rehabilitative treatments (e.g., functional trainings, EMST, } \\
\text { compensatory swallowing maneuvers and head/body postures, and adaptive } \\
\text { dietary strategies and texture modification) }\end{array}$ \\
\hline & $\begin{array}{l}\text { Instrumental techniques used as biofeedback (FEES, VFSS); video-assisted } \\
\text { swallowing therapy, TTS }\end{array}$ \\
\hline & Video fluoroscopy in selected cases to exclude silent aspiration \\
\hline & $\begin{array}{l}\text { Enteral feeding options (short-term nasogastric tube orpercutaneous endoscopic } \\
\text { gastrostomy) }\end{array}$ \\
\hline Sialorrhea & BoNT $^{\S,+,}$ Glycopyrrolate ${ }^{\S, \#}$ \\
\hline Gastrointestinal disturbances & $\begin{array}{l}\text { Constipation: } \text { Macrogol }{ }^{\wedge, \#}, \text { Lubiprostone }^{\wedge \#,} \text { Probiotics and prebiotic fiber }{ }^{\S,+} \\
\text { Nausea and vomiting: Domperidone }{ }^{\wedge \#}\end{array}$ \\
\hline \multirow[t]{7}{*}{ Sleep disturbances } & Insomnia \\
\hline & Hypnotics:Eszopiclone «,\# \\
\hline & Melatonin: 3-5 mg «,\# \\
\hline & DAA:Rotigotine ${ }^{\wedge, \#}$ (cautious use, monitor AEs) \\
\hline & Nonpharmacological interventions - CPAP (in patients with OSA) ${ }^{\wedge, \#}$ \\
\hline & Day-time sleepiness: Modafinil ${ }^{\ll, \# ~(n o ~ s t u d y ~ i n ~ L S P D) ; ~ C P A P ~ f o r ~ O S A ~}$ \\
\hline & $\begin{array}{l}\text { Recommendations: a) Improve nocturnal sleep by reducing akinesia, tremor and } \\
\text { urinary frequency; b) reduce/discontinue day-time sedative drugs or DAAs for } \\
\text { day-time sleepiness }\end{array}$ \\
\hline \multirow[t]{2}{*}{ Urinary symptoms } & $\begin{array}{l}\text { Solifenacin «\# (Other anticholinergics have insufficient evidence and cognition } \\
\text { may worsen) }\end{array}$ \\
\hline & $\begin{array}{l}\text { Recommendations: ruling out urinary tract infection and, in men, outflow } \\
\text { obstruction by benign prostatic hyperplasia. Nocturia: reduce intake of fluid } \\
\text { after } 6 \mathrm{pm} \text { and sleep with head-up tilt of bed to reduce urine production }\end{array}$ \\
\hline \multirow[t]{5}{*}{ Pain \& Joint Deformities } & $\begin{array}{l}\text { Oxycodon/naloxone prolonged release }{ }^{\ll, \# ~(c a u t i o u s ~ u s e ~ d u e ~ t o ~ i n c r e a s e d ~ r i s k ~ f o r ~} \\
\text { life-threatening respiratory depression in elderly cachetic patients) }\end{array}$ \\
\hline & Only GPP level \\
\hline & $\begin{array}{l}\text { Frozen Shoulder: Physiotherapy, Oral corticosteroids, Corticosteroid injections, } \\
\text { Capsular distension; }\end{array}$ \\
\hline & $\begin{array}{l}\text { Dystonia across joints: adjust dopaminergic medication, BoNT, Bacofen, Tendon } \\
\text { surgery; }\end{array}$ \\
\hline & $\begin{array}{l}\text { Join pain: Anti-inflammatories, Analgesics, Gabapentin, Pregabalin, } \\
\text { Corticosteroid intra-articular injections, Joint-replacement surgery; }\end{array}$ \\
\hline
\end{tabular}


Table 1

(continued)

Late Stage PD

Clinical features

Recommendations: a) try to understand if dystonic-associated or

non-dystonic-associated pain, such as central, neuropathic or radicular,

musculoskeletal and akathisia discomfort; b) consider possible coexistence of

different pain syndromes in the same patient; c) investigate join and skeletal

deformities

Integrated palliative care

Aim: implement an optimal symptomatic control, educational and emotional support of patients and caregivers, guidance of home adaptation, improve the management of issues related to future care planning, psychosocial and spirituality issues, death and bereavement;

Delivered by: a multidisciplinary team (PC specialist, neurologist trained in PC, PC nurse, psychologist, physiotherapist, speech therapist, social worker, dietician and chaplaincy)

Level of evidences as reported by Seppi et al., 2019 [24]; Fox et al., 2018 [22], Ferreira et al., 2013 [23]. $(\S)$ Efficacious, $(\wedge)$ Likely efficacious, $(\infty)$ unlikely efficacious, («) insufficient evidence, (+) clinically useful, (\#) possibly useful, (x) investigational; (GPP): Good practice point; Level C: based on non-comparative trials; PD, Parkinson's disease; HY, Hoehn \& Yahr scale; S\&E, Schwab and England Activities of Daily Living scale; FoG, freezing of gait; MMSE, Mini-Mental State Examination; NMS, non motor symptoms; NPI-12 items, The Neuropsychiatric Inventory Questionnaire; NMSS, Non-Motor Symptoms Scale for Parkinson's Disease; QoL, quality of life; PDQ-8, Parkinson's Disease Questionnaire-8; ESAS, Edmonton Symptom Assessment Scale; L-dopa, levodopa; DA, dopamine agonists; IMAO-B, Monoamine oxidase B inhibitors; COMT-I, Catechol-O-methyltransferase inhibitors; SSRI, selective serotonin reuptake inhibitors; SSNRI, selective serotonin norepinephrine reuptake inhibitors; LSVT, Lee Silverman Voice Therapy; BoNT, botulinum toxin injection; EMST, expiratory muscle straightening training; FEES, fiberoptic endoscopic evaluation of swallowing; VFSS, video fluoroscopic swallowing study; VAST, video-assisted swallowing therapy; TTS, thermal-tactile stimulation; CPAP, continuous positive airway pressure; OSA, obstructive sleep apnea; PC, palliative care.

such a milder levodopa responsiveness does not seem to be a risk for death [4] (Table 1).

\section{Who is affected?}

LSPD disability has a major impact not only on patients' quality of life (QoL), but also on relatives and/or caregivers, who carry themselves a high physical, psychological and socioeconomic burden. Failure to acknowledge and properly manage caregivers' burden may ultimately lead to burnout, diminishing their effectiveness and capacity to maintain their informal partner role in treatment, therefore creating an "invisible patient". This may also lead to premature institutionalization of such patients, with an associated cost increase [16].

\section{INSTITUTIONALIZATION AND MORTALITY}

Around $20 \%$ of LSPD patients are institutionalized $[4,17,18]$, usually in nursing homes and not in assisted living facilities, as they are mostly dependent in activities of daily living (ADLs), needing medical care and supervision. Psychosis is a risk factor for institutionalization, with $25 \%$ of PD patients with psychosis being institutionalized vs. one in ten patients without psychosis [19].
Pneumonia and food aspiration are listed among the most frequent death causes [4], which is influenced by older age, dementia and severe axial symptoms [20, 21]. However, no study has specifically assessed mortality causes among LSPD patients, as it may frequently happen that those frail patients are no longer followed by their treating physician during the last years/months of life.

\section{THERAPEUTIC RECOMMENDATIONS}

\section{Pharmacological treatment}

No randomized controlled clinical trials (RCTs) specifically addressed LSPD patients as a target population. Hence, a scarce amount of systematic data exist for the treatment of motor and NMS of LSPD patients, and treatment recommendations are frequently based on expert opinions and good clinical practice (Table 1) [24]. Table 1 summarizes the pharmacological and non-pharmacological interventions for the most common motor and NMS of LSPD, based on the Movement Disorder Society (MDS) Evidence-Based Medicine (EBM) Reviews or the European Federation of Neurological Society guidelines [22-24]. However, those recommendations are based on RCTs that classically do not include LSPD patients [25]. 
Overall, levodopa is the gold standard of PD treatment, even in LS (Table 1) [4, 26, 27]. LSPD tremor dominant patients, with no dementia and who still present MCs have the better responsiveness profile and may benefit from a cautious dose increment, when clinically indicated $[15,26]$. Additionally, due to the frequent occurrence of adverse events (AEs) induced by anti parkinsonian drugs, a regimen simplification of treatment strategy, based on the unique use of levodopa and drugs for psychosis/dementia is recommended [10]. Conversely, no acute effect of levodopa has been observed on several NMS, such as pain, anxiety, fatigue and axial symptoms, i.e., speech, postural instability, posture and FoG [4, 28, 29]. On a related note, a mild acute response should not be translated into a levodopa ineffectiveness nor in recommendations for drug suspension or decrement, in absence of AEs. The levodopa "longduration response" should be taken into account, even in this latest stage [30].

\section{Nonpharmacological treatments}

Considering the last MDS-EBM update [22] on treatments for PD motor symptoms, with the exception of physiotherapy which is "likely efficacious", exercise-based movement strategies, formalized pattern exercises, speech therapy, and occupational therapy, were all deemed "possibly useful", not with standing insufficient evidence regarding efficacy, to date (Table 1) [22].

Within the non-phamacological approaches for LSPD we believe that it is worth to consider also palliative care (PC) and health-care models.

\section{Palliative care}

PC includes a broad range of "aims to improve the QoL of patients and their families with lifethreatening illness" (Table 1). PC no longer restricts to "end-of-life care", seeking to appease suffering along the entire course of the illness [31]. Given the complex clinical picture of LSPD patients, an implementation of $\mathrm{PC}$ interventions is desirable, integrated with traditional care and variably delivered as inpatient or outpatient PC, hospice care or at home PC nursing, in agreement with patients' needs. Additionally, advance care planning, a component of PC, which provides a vehicle through which patients, families, and clinicians can collaborate to identify values, goals, and preferences regarding future medical care, could be particularly helpful. Indeed, LSPD patients often present with all the red flags for unmet PC needs, which should "trigger" specialized PC referral. These that are: swallowing problems, recurrent infections, marked decline in physical function, first aspiration pneumonia, cognitive difficulties, weight loss and significant complex symptoms [32]. Identifying these red flags could help with the practical application of integrated models of care.

\section{Health care models}

The complex clinical picture of LSPD patients suggests adoption of an individualized and multispecialty care approach. Multispecialty models of care can be organized as: a) multidisciplinary care: each discipline is responsible for a specific patient need without a standardized coordination; b) interdisciplinary care: healthcare team members collaborate and make group decisions; c) integrated care: a care plan involving multiple members of a healthcare team is guided by consensus building and engagement of patients as team members [33-35]. However, results of past trials on both multidisciplinary or integrated care models have suggested heterogeneous results, from no change to a small/moderate benefit in QoL [36-38], though no trials on integrated care were specifically addressed to LSPD patients. Of note, a recent observational study on a home visit care model has found a good satisfaction and feasibility of the model, even among HY 4-5 PD patients [39].

\section{HOW TO ASSESS LATE STAGE PD PATIENTS}

A proper assessment of a LSPD patient should be always made in co-presence with the principal formal or informal caregiver, due to the high prevalence of dementia. A Schwab and England Activities of Daily Livingscale $<50 \%$ has been proposed as operational clinical criterionto identify LSPD patients (Fig. 1) [2].

Healthcare professionals should actively investigate, the presence of falls, hallucinations, choking episodes, cognitive decline, sleep and urinary disturbances. Among those symptoms, swallowing problems should receive particular attention, and a prompt assessment by a phoniatrician should be considered on a regular basis. To date, no specific questionnaires have been created for demented LSPD patients. However, a European multicenter study has been recently developed (see below) [40] with the aim of characterizing a large population of LSPD patients; questionnaires adopted in this study may be 
considered as a sort of guideline to assess these patients (Table 1).

\section{BOTTLENECKS}

LSPD patients' assessment and treatment reflect a long list of clinical unmet needs [41]. Most of the instruments available to assess LSPD patients seem to be partially adequate or mostly inadequate, probably because clinometric properties of such scales have not been specifically tested among LSPD patients, who are difficultly testable due to dementia, behavioral disorders and severe dysarthria. Equally, non-pharmacological interventions are not adapted to these frail and demented patients. This is one of the reason why, when we extrapolate data of HY 4-5 patients from small trials on multidisciplinary or home-based exercise and strategy training, no improvement is found, for instance, on ADLs or falls [41, 42]. Additionally, the neuropathology of levodopa unresponsive motor or NMS, remains largely undefined, besides the fact there are no new marketed drugs that properly target those symptoms [43]. Finally, the management of LSPD patients previously submitted to device-aided therapies may be particularly challenging, with no guideline available to help clinicians to manage this sub-group of LSPD patients, including the possible discontinuation of on-going advanced therapies.

\section{ONGOING RESEARCHES}

Several clinical studies and trials are currently ongoing on LSPD.

The results of a longitudinal, multicentre, prospective cohort study, i.e., Care of Late-Stage Parkinsonism (CLaSP), which assessed the needs and provision of care for patients with LSPD and their caregivers in six European countries (UK, France, Germany, Netherlands, Portugal, Sweden) will be shortly published [40]. A PC model that could be integrated in traditional care is also being evaluated in a multinational European project (http://www.pdpal.eu), though it will not focus only on LSPD. In UK, OPTCARE Neuro, a multicentre RCT evaluating the short-term effectiveness of short-term integrated PC in long-term neurological conditions, including PD, is ongoing [44]. In the USA, a randomized multicentre, comparative effectiveness trial of team-based outpatient PC versus usual care for PD patients with moderate to severe PC needs, has begun [45]. Another trial on interdisciplinary home PC model (IN-HOME PD; NCT03189459), focused on HY3-5 homebound PD patients, is currently ongoing in the USA, and will be completed in late 2020 . Finally, the results of an Italian multicentre study that has explored the effect of deep brain stimulation among LSPD patients, in order to develop a decisional algorithm to rule a possible stimulation discontinuation, will be shortly published.

\section{FUTURE PERSPECTIVES}

Researches on the LSPD domain should be focussed on several targets and steps: a) basic research: to develop non-dopaminergic drugs that may tackle the extra-dopaminergic dysfunction, and improve the tolerability profile of anti parkinsonian agents; b) clinical assessment and non-pharmacological treatments: develop adapted assessment tools and rehabilitation strategies for demented homebound LSPD patients; c) environment: to consider the family caregiver as well as the environment as therapeutic targets; d) healthcare models: based on the shortcomings of the present institution-based medical approach [46] and the frequent need for LSPD to be visited at home [4], this population could be the proper target for an in-home integrated care trial.

Overall, an effort should be made to include LSPD patients in clinical studies, as this "orphan population" is likely to increase, and may represent a model to tackle disability milestones of neurodegenerative diseases.

\section{ACKNOWLEDGMENTS}

The present study has no funding.

\section{CONFLICT OF INTEREST}

The authors have no conflict of interest to report.

Dr. Margherita Fabbri: grant from AbbVie. Dr. Kauppila: nothing to disclose. Professor Joaquim J. Ferreira: Consultancies: Ipsen, GlaxoSmithKline, Novartis, Teva, Lundbeck, Solvay, Abbott, BIAL, Merck-Serono and Merz; Grants: GlaxoSmithKline, Grunenthal, Teva and Fundação MSD. Professor Olivier Rascol: Advisory Boards and Consultancy: AbbVie, Adamas, Acorda, Addex, AlzProtect, Apopharma, Astrazeneca, Axovant, Bial, Biogen, Britannia, Buckwang, Cerespir, Clevexel, 
Denali, INC Reasearch, Lundbeck, Lupin, Merck, MundiPharma, Neuratris, Neuroderm, Novartis, ONO Pharma, Osmotica, Parexel, Pfizer, Prexton Therapeutics, Quintiles, Roche, Sanofi, Servier, Sunovion, Théranexus, Takeda, Teva, UCB, Vectura, Watermark Research, XenoPort, XO, Zambon; Grant: Agence Nationale de la Recherche (ANR), CHU de Toulouse, France-Parkinson, INSERMDHOS Recherche Clinique Translationnelle, MJFox Foundation, Programme Hospitalier de Recherche Clinique, European Commission (FP7, H2020), Cure Parkinson IK; Other: Grant to participate in a symposium and contribute to the review of an article IPMDS.

\section{REFERENCES}

[1] Dorsey ER, Bloem BR (2018) The Parkinson pandemic-a call to action. JAMA Neurol 75, 9-10.

[2] Coelho M, Ferreira JJ (2012) Late-stage Parkinson disease. Nat Rev Neurol 8, 435-442.

[3] Velseboer DC, Broeders M, Post B, van Geloven N, Speelman JD, Schmand B, de Haan RJ, de Bie RM (2013) Prognostic factors of motor impairment, disability, and quality of life in newly diagnosed PD. Neurology 80, 627-633.

[4] Fabbri M, Coelho M, Abreu D, Guedes LC, Rosa MM, Godinho C, Cardoso R, Guimaraes I, Antonini A, Zibetti M, Lopiano L, Ferreira JJ (2019) Dysphagia predicts poor outcome in late-stage Parkinson's disease. Parkinsonism Relat Disord 64, 73-81.

[5] Antonini A, Stoessl AJ, Kleinman LS, Skalicky AM, Marshall TS, Sail KR, Onuk K, Odin PLA (2018) Developing consensus among movement disorder specialists on clinical indicators for identification and management of advanced Parkinson's disease: A multi-country Delphipanel approach. Curr Med Res Opin 34, 2063-2073.

[6] Fasano A, Fung VSC, Lopiano L, Elibol B, Smolentseva IG, Seppi K, Takats A, Onuk K, Parra JC, Bergmann L, Sail K, Jalundhwala Y, Pirtosek Z (2019) Characterizing advanced Parkinson's disease: OBSERVE-PD observational study results of 2615 patients. BMC Neurol 19, 50 .

[7] Goetz CG, Poewe W, Rascol O, Sampaio C, Stebbins GT, Counsell C, Giladi N, Holloway RG, Moore CG, Wenning GK, Yahr MD, Seidl L (2004) Movement Disorder Society Task Force report on the Hoehn and Yahr staging scale: Status and recommendations. Mov Disord 19, 1020-1028.

[8] Kalia LV, Lang AE (2015) Parkinson's disease. Lancet 386, 896-912.

[9] Coelho M, Marti MJ, Sampaio C, Ferreira JJ, Valldeoriola F, Rosa MM, Tolosa E (2015) Dementia and severity of parkinsonism determines the handicap of patients in late-stage Parkinson's disease: The Barcelona-Lisbon cohort. Eur J Neurol 22, 305-312.

[10] Coelho M, Marti MJ, Tolosa E, Ferreira JJ, Valldeoriola F, Rosa M, Sampaio C (2010) Late-stage Parkinson's disease: The Barcelona and Lisbon cohort. J Neurol 257, 1524-1532.

[11] Romagnolo A, Fabbri M, Merola A, Montanaro E, Palermo S, Martone T, Seresini A, Goldwurm S, Rizzone MG, Lopiano L (2018) Beyond 35 years of Parkinson's disease: A comprehensive clinical and instrumental assessment. J Neurol 265, 1989-1997.
[12] Rosqvist K, Horne M, Hagell P, Iwarsson S, Nilsson MH, Odin P (2018) Levodopa effect and motor function in late stage Parkinson's disease. J Parkinsons Dis 8, 59-70.

[13] Hely MA, Reid WGJ, Adena MA, Halliday GM, Morris JGL (2008) The Sydney multicenter study of Parkinson's disease: The inevitability of dementia at 20 years. Mov Disord 23, 837-844.

[14] Kempster PA, O'Sullivan SS, Holton JL, Revesz T, Lees AJ (2010) Relationships between age and late progression of Parkinson's disease: A clinico-pathological study. Brain 133, 1755-1762.

[15] Fabbri M, Coelho M, Abreu D, Ferreira JJ (2019) Levodopa response in later stages of Parkinson's disease: A case-control study. Parkinsonism Relat Disord, doi: 10.1016/j.parkreldis.2019.10.027.

[16] Mosley PE, Moodie R, Dissanayaka N (2017) Caregiver burden in Parkinson disease: A critical review of recent literature. J Geriatr Psychiatry Neurol 30, 235-252.

[17] Hand A, Gray WK, Oates LL, Woolford M, Todd A, Bale E, Jones C, Wood BH, Walker RW (2016) Medication use in people with late stage Parkinson's disease and parkinsonism living at home and in institutional care in north-east England: A balance of symptoms and side-effects? Parkinsonism Relat Disord 32, 120-123.

[18] Safarpour D, Thibault DP, DeSanto CL, Boyd CM, Dorsey ER, Racette BA, Willis AW (2015) Nursing home and end-of-life care in Parkinson disease. Neurology 85, 413-419.

[19] Wetmore JB, Li S, Yan H, Irfan M, Rashid N, Peng Y, Gilbertson DT, Shim A (2019) Increases in institutionalization, healthcare resource utilization, and mortality risk associated with Parkinson disease psychosis: Retrospective cohort study. Parkinsonism Relat Disord 68, 95-101.

[20] Pinter B, Diem-Zangerl A, Wenning GK, Scherfler C, Oberaigner W, Seppi K, Poewe W (2015) Mortality in Parkinson's disease: A 38-year follow-up study. Mov Disord 30, 266-269.

[21] Zhang Y, Wang C, Wang Y, Xiao Q, Liu J, Ma J, Zhou H, Pan J, Tan Y, Chen S, Xu G, Wang G (2018) Mortality from Parkinson's disease in China: Findings from a ten-year follow up study in Shanghai. Parkinsonism Relat Disord 55, 75-80.

[22] Fox SH, Katzenschlager R, Lim SY, Barton B, de Bie RMA, Seppi K, Coelho M, Sampaio C (2018) International Parkinson and movement disorder society evidence-based medicine review: Update on treatments for the motor symptoms of Parkinson's disease. Mov Disord 33, 1248-1266.

[23] Ferreira JJ, Katzenschlager R, Bloem BR, Bonuccelli U, Burn D, Deuschl G, Dietrichs E, Fabbrini G, Friedman A, Kanovsky P, Kostic V, Nieuwboer A, Odin P, Poewe W, Rascol O, Sampaio C, Schupbach M, Tolosa E, Trenkwalder C, Schapira A, Berardelli A, Oertel WH (2013) Summary of the recommendations of the EFNS/MDS-ES review on therapeutic management of Parkinson's disease. Eur J Neurol 20, 5-15.

[24] Seppi K, Ray Chaudhuri K, Coelho M, Fox SH, Katzenschlager R, Perez Lloret S, Weintraub D, Sampaio C (2019) Update on treatments for nonmotor symptoms of Parkinson's disease-an evidence-based medicine review. Mov Disord 34, 180-198.

[25] Bloem BR, de Vries NM, Ebersbach G (2015) Nonpharmacological treatments for patients with Parkinson's disease. Mov Disord 30, 1504-1520.

[26] Fabbri M, Coelho M, Abreu D, Guedes LC, Rosa MM, Costa N, Antonini A, Ferreira JJ (2016) Do patients with late-stage 
Parkinson's disease still respond to levodopa? Parkinsonism Relat Disord 26, 10-16.

[27] Olanow CW, Stocchi F (2018) Levodopa: A new look at an old friend. Mov Disord 33, 859-866.

[28] Fabbri M, Coelho M, Guedes LC, Chendo I, Sousa C, Rosa MM, Abreu D, Costa N, Godinho C, Antonini A, Ferreira JJ (2017) Response of non-motor symptoms to levodopa in late-stage Parkinson's disease: Results of a levodopa challenge test. Parkinsonism Relat Disord 39, 37-43.

[29] Fabbri M, Guimaraes I, Cardoso R, Coelho M, Guedes LC, Rosa MM, Godinho C, Abreu D, Goncalves N, Antonini A, Ferreira JJ (2017) Speech and voice response to a levodopa challenge in late-stage Parkinson's disease. Front Neurol 8, 432.

[30] Nagao K, Ding C, Ganga G, Alty JE, Clissold BG, McColl CD, Reardon KA, Schiff M, Kempster PA (2019) Inferring the long duration response to levodopa in Parkinson's disease. Parkinsonism Relat Disord 60, 133-137.

[31] Bouca-Machado R, Lennaerts-Kats H, Bloem B, Ferreira JJ (2018) Why palliative care applies to Parkinson's disease. Mov Disord 33, 750-753.

[32] Bouca-Machado R, Titova N, Chaudhuri KR, Bloem BR, Ferreira JJ (2017) Palliative care for patients and families with Parkinson's disease. Int Rev Neurobiol 132, 475-509.

[33] van der Marck MA, Bloem BR (2014) How to organize multispecialty care for patients with Parkinson's disease. Parkinsonism Relat Disord 20(Suppl 1), S167-173.

[34] Cohen EV, Hagestuen R, Gonzalez-Ramos G, Cohen HW, Bassich C, Book E, Bradley KP, Carter JH, Di Minno M, Gardner J, Giroux M, Gonzalez MJ, Holten S, Joseph R, Kornegay DD, Simpson PA, Tomaino CM, Vandendolder RP, Walde-Douglas M, Wichmann R, Morgan JC (2016) Interprofessional education increases knowledge, promotes team building, and changes practice in the care of Parkinson's disease. Parkinsonism Relat Disord 22, 21-27.

[35] Qamar MA, Harington G, Trump S, Johnson J, Roberts F, Frost E (2017) Multidisciplinary care in Parkinson's disease. Int Rev Neurobiol 132, 511-523.

[36] van der Marck MA, Munneke M, Mulleners W, Hoogerwaard EM, Borm GF, Overeem S, Bloem BR (2013) Integrated multidisciplinary care in Parkinson's disease: A non-randomised, controlled trial (IMPACT). Lancet Neurol 12, 947-956.
[37] Eggers C, Dano R, Schill J, Fink GR, Timmermann L, Voltz R, Golla H, Lorenzl S (2018) Access to end-of life Parkinson's disease patients through patient-centered integrated healthcare. Front Neurol 9, 627.

[38] Tan SB, Williams AF, Kelly D (2014) Effectiveness of multidisciplinary interventions to improve the quality of life for people with Parkinson's disease: A systematic review. Int J Nurs Stud 51, 166-174.

[39] Fleisher J, Barbosa W, Sweeney MM, Oyler SE, Lemen AC, Fazl A, Ko M, Meisel T, Friede N, Dacpano G, Gilbert RM, Di Rocco A, Chodosh J (2018) Interdisciplinary home visits for individuals with advanced Parkinson's disease and related disorders. J Am Geriatr Soc 66, 1226-1232.

[40] Balzer-Geldsetzer M, Ferreira J, Odin P, Bloem BR, Meissner WG, Lorenzl S, Wittenberg M, Dodel R, Schrag A (2018) Study protocol: Care of Late-Stage Parkinsonism (CLaSP): A longitudinal cohort study. BMC Neurol 18, 185.

[41] Van de Weijer SCF, Hommel A, Bloem BR, Nonnekes J, De Vries NM (2018) Promising non-pharmacological therapies in PD: Targeting late stage disease and the role of computer based cognitive training. Parkinsonism Relat Disord 46(Suppl 1), S42-s46.

[42] Canning CG, Sherrington C, Lord SR, Close JC, Heritier S, Heller GZ, Howard K, Allen NE, Latt MD, Murray SM, O'Rourke SD, Paul SS, Song J, Fung VS (2015) Exercise for falls prevention in Parkinson disease: A randomized controlled trial. Neurology 84, 304-312.

[43] Charvin D, Medori R, Hauser RA, Rascol O (2018) Therapeutic strategies for Parkinson disease: Beyond dopaminergic drugs. Nat Rev Drug Discov 17, 804-822.

[44] Hepgul N, Gao W, Evans CJ, Jackson D, van Vliet LM, Byrne A, Crosby V, Groves KE, Lindsay F, Higginson IJ (2018) Integrating palliative care into neurology services: What do the professionals say? BMJ Support Palliat Care 8, 41-44.

[45] Kluger BM, Katz M, Galifianakis N, Pantilat SZ, Kutner JS, Sillau S, Gritz M, Jones J, Fairclough D, Sumrall M, Hall K, Miyasaki J (2019) Does outpatient palliative care improve patient-centered outcomes in Parkinson's disease: Rationale, design, and implementation of a pragmatic comparative effectiveness trial. Contemp Clin Trials 79, 28-36.

[46] Dorsey ER, Vlaanderen FP, Engelen LJ, Kieburtz K, Zhu W, Biglan KM, Faber MJ, Bloem BR (2016) Moving Parkinson care to the home. Mov Disord 31, 1258-1262. 